$(43 \%)$ of yellow prisms of II, mp 348-350 ${ }^{\circ}\left(\right.$ lit.9) $\left.358-360^{\circ}\right)$. Anal. Calcd. for $\mathrm{C}_{12} \mathrm{H}_{12} \mathrm{O}_{4} \mathrm{~N}_{6}: \mathrm{C}, 47.33 ; \mathrm{H}$, $3.98 ; \mathrm{N}, 27.62$. Found: C, 47.59; H. 3.78; N. 27.90.

(B) A mixture of $1.7 \mathrm{~g}$ (0.01 mole) of 5,6-diamino-1,3-dimethyluracil and $1.4 \mathrm{~g}(0.01 \mathrm{~mole})$ of anthranilic acid was fused at $200^{\circ}$ for $1 \mathrm{hr}$. After cooling the reaction mixture was recrystallized from DMF to give $0.5 \mathrm{~g}$ of II, which was identical with the product obtained above.

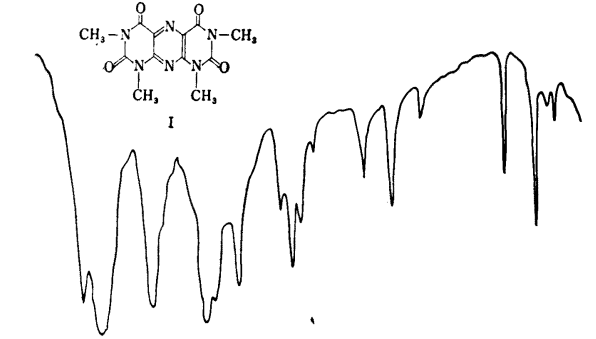

180017001600150014001300120011001000900800700

Fig. 1a. IR Spectrum of I (in Nujol)

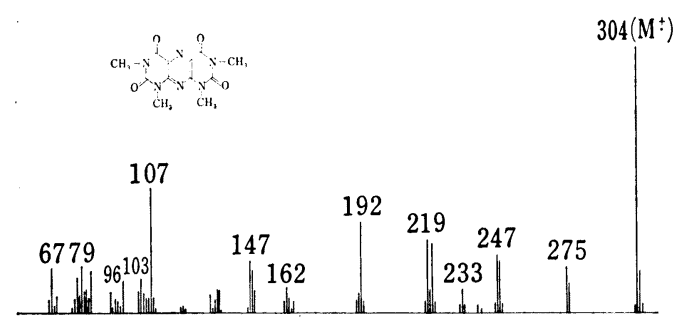

Fig. 2a. Mass Spectrum of I $(75 \mathrm{eV})$

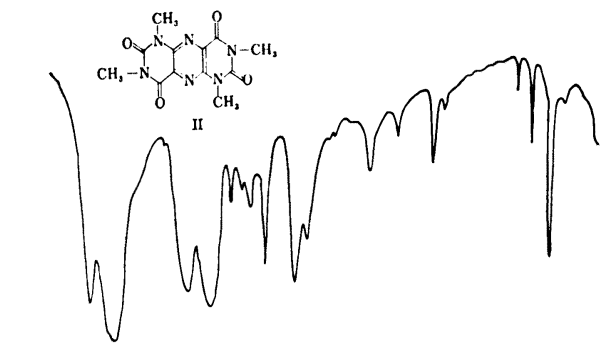

180017001600150014001300120011001000900800700

Fig. 1b. IR Spectrum of II (in Nujol)

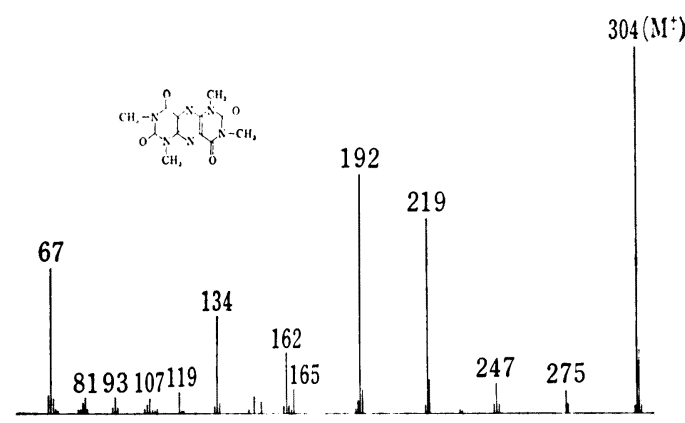

Fig. 2b. Mass Spectrum of II $(75 \mathrm{eV})$

\title{
Effect of Penicillamine on the Glycosaminoglycan Composition of Rat Aorta
}

Yo Mori, Kazushige Tanuma, Shinkichi Ninobe, ${ }^{1 a}$ and Riza Bashey ${ }^{1 b}$

Tokyo College of Pharmacy $\left.{ }^{1 a}\right)$ and Department of Pathology, Albert Einstein College of Medicine $e^{1 b)}$

(Received November 25, 1970)

Administration of penicillamine ( $\beta, \beta$-dimethylcysteine) results in a great loss of strength of skin with increase in solubility of collagen as in lathyrism. ${ }^{2)}$ However, the chemical nature of penicillamine and the difference in its effect on crosslinking formation of elastin and col-

1) Location: a) 20, Kitashinjuku 3-chome, Shinjuku-ku, Tokyo; b) 1300 Morris Park Avenue, Bronx, New York, 10461, U.S.A.

2) M.E. Nimni, J. Biol. Chem., 243, 1457 (1968). 
lagen, suggest a different mechanism of action from that of lathyrogen such as $\beta$-aminopropionitrile. ${ }^{2-4)}$

Previous investigation of penicillamine dealt almost exclusively with the mode of action of collagen and elastin maturation, but there is no information available concerning the glycosaminoglycan.

A preliminary investigation was undertaken, therefore, to study the alteration of glycosaminoglycan as well as collagen in aorta when penicillamine was given to rats.

\section{Experimental}

Animals - Young male Wistar rats, weighing $60-80 \mathrm{~g}$ the beginning of the experiment, were used. The treated rats were maintained on a diet which contained $0.25 \%$ D-penicillamine and supplemented with $100 \mathrm{mg}$ of pyridoxine per $\mathrm{kg}$ of diet. After 14 days, control and treated rats were killed by decapitation. The aorta was rapidly excised and adhering tissue was cleaned off. The pooled aorta was defatted and dried to a constant weight.

Extraction and Fractionation of Glycosaminoglycan-Extraction of glycosaminoglycan was carried out by the method of Schiller, et al. ${ }^{5)}$ Crude glycosaminoglycans obtained were fractionated by cellulose column chromatography according to Thunell, et. al. ${ }^{6}$ ) The columns were eluted with $1 \%$ cetylpyridinum chloride (CPC), $0.3 \mathrm{M} \mathrm{NaCl}, 0.28 \mathrm{M} \mathrm{MgCl}_{2}, 0.75 \mathrm{M} \mathrm{MgCl}_{2}$, and finally with $3 \mathrm{M} \mathrm{NaCl}$. All salt solutions contained $0.05 \%(\mathrm{w} / \mathrm{v})$ CPC. Each fraction was analysed for uronic acid by the carbazole reaction as modified by Bitter and Muir. ${ }^{7}$ ) After removing CPC with $\mathrm{KCNS}$, each fraction was subjected to electrophoretic separation using cellulose acetate as described by Prout.8) After staining with Alician Blue, the strip was scanned on Fuji densitometer FD AIV using an orange color filter.

Fractionation of Aortic Collagen_- To examine the fractionation of salt soluble collagen and its separation from the insoluble fraction in aorta, aorta minces were homogenized with cold $0.45 \mathrm{M} \mathrm{NaCl}$ in $0.02 \mathrm{M}$ solution of Tris buffer ( $\mathrm{pH} 7.4$ ), in a glass homogenizer. Homogenates were shaken twice at $4^{\circ}$, for $24 \mathrm{hr}$ each time and then centrifuged (salt soluble collagen fraction). The final residues containing the insoluble collagen were solubilized with $0.3 \mathrm{M}$ trichloroacetic acid at $90^{\circ}$ tiwce ${ }^{\text {) }}$ (insoluble collagen fraction). Both soluble and insoluble fractions after dialysis against water were each evaporated and hydrolyzed in $6 \mathrm{~N} \mathrm{HCl}$ by heating in a sealed tube for $18 \mathrm{hr}$ at $110^{\circ}$. Hydroxyproline was measured by modified Prockop method..$^{10}$

\section{Result and Discussion}

Analysis of aortic glycosaminoglycan from rats treated with penicillamine for 14 days revealed a marked elevation of uronic acid in the fraction eluted with $0.75 \mathrm{M} \mathrm{MgCl}_{2}$ as shown in Table I and it was confirmed by electrophoresis that this fraction consists of chondroitin sulfate $\mathrm{A} / \mathrm{C}$ and $\mathrm{B}$. Further, it was concluded from densitometry that the increased chondroitin sulfate content of aorta treated with penicillamine was for the most part due to elevated amount of chondroitin sulfate A/C (Fig. 1). The $0.28 \mathrm{M} \mathrm{MgCl}_{2}$ fraction was also slightly increased. This fraction separated into two components on electrophoresis in zinc acetate. It was assumed from the results of testicular hyaluronidase digestion that the major component was heparan sulfate, but differing from standard heparan sulfate obtained from beef lung. The fastest component was digested by testicular hyaluronidase, corresponding in mobility to standard chondroitin sulfate A/C.

On the other hand, the amount of collagen extracted by $0.45 \mathrm{~m} \mathrm{NaCl}$ solution was markedly increased in the treated group. A comparison of pattern of collagen solubility in the aorta of these animals is shown in Table II.

3) S.R. Pinnell, G.R. Martin, and E.J. Miller, Science, 161, 475 (1968).

4) K. Deshmukh and M.E. Nimni, J. Biol. Chem., 244, 1787 (1969).

5) S. Schiller, G.A. Slover, and A. Dorfman, J. Biol. Chem., 236, 983 (1961).

6) S. Thunell, C.A. Antonopoulos, and S. Gardell, J. Atheroscler. Res., 7, 283 (1967).

7) T. Bitter and H. Muir, Anal. Biochem., 4, 330 (1962).

8) R.E.S. Prout, Biochim. Biophys. Acta, 177, 157 (1969).

9) S.M. Fitch, M.L.R. Harkness, and R.D. Harkness, Nature, 176, 163 (1955).

10) K.I. Kivirikko, O. Latinen, and D.J. Prockop, Anal. Biochem., 19, 249 (1967). 
TABLe I. Effect of Penicillamine on the Glycosaminoglycan Composition of Rat Aorta

\begin{tabular}{ccccccccc}
\hline Group & $\begin{array}{c}\text { Av. body } \\
\text { weight } \\
(\mathrm{g})\end{array}$ & $\begin{array}{c}\text { Aorta } \\
\text { wet weight } \\
(\mathrm{mg} / \mathrm{Rat})\end{array}$ & $0.3 \mathrm{M} \mathrm{NaCl}$ & $\mathbf{0 . 2 8 \mathrm { M } \mathrm { MgCl } _ { 2 }}$ & $\mathbf{0 . 7 5 \mathrm { M } \mathrm { MgCl } _ { 2 }}$ & $3 \mathrm{M} \mathrm{NaCl}$ & Total \\
\hline Control (5) & 144 & $33.5 \pm 1.8$ & $47.5 \pm 11.0$ & $39.1 \pm 4.8$ & $82.0 \pm 14.9$ & trace & $169.0 \pm 28.7$ \\
Treated (5) & 141 & $52.4 \pm 3.2$ & $48.0 \pm 5.2$ & $57.2 \pm 3.1^{b)}$ & $198.0 \pm 14.1^{c)}$ & trace & $294.2 \pm 16.6^{d)}$ \\
\hline
\end{tabular}

Figures in parentheses indicate the number of analyses in each group.

a) $\mu \mathrm{g}$ glucuronolactone $/ 100 \mathrm{mg}$ dried aorta

b) significantly different from control value $(p<0.02)$

c) $(p<0.001)$

d) $(p<0.01)$
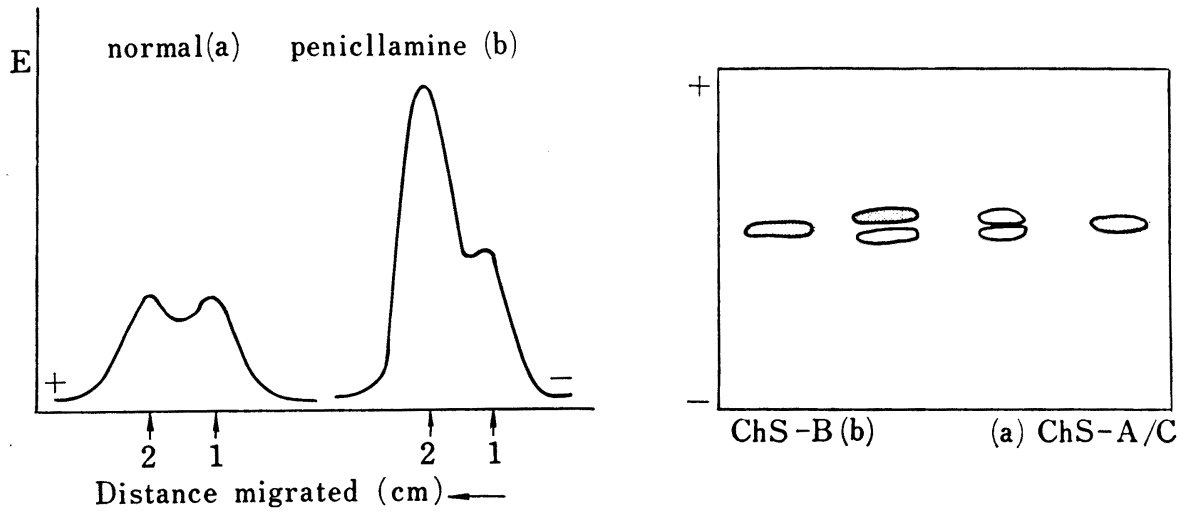

Fig. 1. Electrophoretic Pattern of the Fraction eluted from the CPC-cellulose Column with $0.75 \mathrm{M} \mathrm{MgCl}_{2}$

Electrophoretic migration is indicated by the arrow; $1=\mathrm{ChS}-\mathrm{B} ; 2=\mathrm{ChS}-\mathrm{A} / \mathrm{C}$. Electrophoresis on cellulose acetate in $0.1 \mathrm{M}$ zinc acetate, $0.25 \mathrm{~mA} / \mathrm{cm}$ for $2 \mathrm{hr}$. Both were stained with Alician Blue, cleaned, and scanned with the Fuji densitometer FD-AIV.

TABLE II. Effect of Penicillamine on Collagen Maturation of Rat Aorta

\begin{tabular}{ccccc}
\hline \hline \multirow{2}{*}{ Group } & $\begin{array}{c}\text { Av. body } \\
\text { weight }\end{array}$ & $0.45 \mathrm{M} \overbrace{\mathrm{NaCl} \text { soluble }}$ & Insoluble & Total \\
\hline Control (3) & $143^{b)}$ & $33.03 \pm 4.5$ & $858.2 \pm 76.2$ & $891.2 \pm 74.7$ \\
Treated (3) & 134 & $61.2 \pm 6.4$ & $874.8 \pm 36.4$ & $936.0 \pm 39.8$ \\
\hline
\end{tabular}

Figures in parentheses indicate the number of analyses in each group.

a) $\mu \mathrm{g}$ hydroxyproline $/ 100 \mathrm{mg}$ wet aorta

b) mean value

The present study confirms chemically that there is an increased concentration of glycosaminoglycan and salt soluble collagen in rat aorta treated with $0.25 \%$ dietary penicillamine. Although many morphological and biochemical studies of experimental lathyrism on glycosaminoglycan have been made, the dispute between those who find decreased levels and those who reported no change has apparently not been settled in lathyritic skin, bone and cartilage. ${ }^{11)}$ However, chemical, histological, and autoradiographic studies have shown that there is a significant elevation in glycosaminoglycan content in lathyritic aorta. ${ }^{11)}$

11) M.L. Tanzer, "International review of connective tissue research," Vol. 3,ed. by D.H. Hall, Academic press, New York, 1965, p. 91. 
In a recent paper, Alper, et al. ${ }^{\mathbf{1 2})}$ proposed the concept that increased glycosaminoglycan concentration found in the lathyritic aorta is a part of non-specific responses to injury. Although administration of penicillamine and lathyrogen such as $\beta$-aminopropionitrile to animals markedly alter their conncetive tissue by preventing the normal crosslinkage of elastin and collagen, the site of inhibition for both compounds are different. ${ }^{2-4)}$ Accordingly, the fact that both penicillamine and $\beta$-aminopropionitrile produced the same increase in chondroitin sulfate $A / C$ would suggest that these changes represent a non-specific responses of aorta to a variety of adverse condition, as presented by Alper, et al. $\left.{ }^{12}\right)$

Acknowledgement The authors are most greatfull to Drs. M.B. Mathews, J.A. Cifonelli, and L. Rodon, the University of Chicago, for the generous supply of standard glycosaminoglycans. The authors are also Roden, indebted to Mr. K. Seki for his excellent technical assistance.

12) R. Alper, J. J.Prior, and W.R. Ruegamer, J. Atheroscler. Res., 8, 787 (1968). 